\title{
OPEN
}

\section{Author Correction: Shear stress induces endothelial-to- mesenchymal transition via the transcription factor Snail}

Marwa M. Mahmoud, Jovana Serbanovic-Canic, Shuang Feng, Celine Souilhol, Rouyu Xing Sarah Hsiao, Akiko Mammoto, Jing Chen, Markus Ariaans, Sheila E. Francis, Kim Van der Heiden, Victoria Ridger@ \& PaulC. Evans

Correction to: Scientific Reports https://doi.org/10.1038/s41598-017-03532-Z, published online 13 June 2017

The Author Contributions section in this Article is incorrect.

“M.M.M., J.S.-C., S.F., C.S., R.X., S.H., M.A. generated, analysed and interpreted data. A.M., J.C., S.E.F., K.V.D.H., V.R. interpreted data and revised the manuscript for important intellectual content. P.C.E. designed the study, interpreted data and wrote the manuscript."

should read:

“M.M.M., J.S.-C., S.F., C.S., R.X., S.H., M.A. generated, analysed and interpreted data. A.M., J.S.-C., J.C., S.E.F., K.V.D.H., V.R. interpreted data and revised the manuscript. P.C.E. designed the study, interpreted data and wrote the manuscript."

\begin{abstract}
(c) (i) Open Access This article is licensed under a Creative Commons Attribution 4.0 International License, which permits use, sharing, adaptation, distribution and reproduction in any medium or format, as long as you give appropriate credit to the original author(s) and the source, provide a link to the Creative Commons license, and indicate if changes were made. The images or other third party material in this article are included in the article's Creative Commons license, unless indicated otherwise in a credit line to the material. If material is not included in the article's Creative Commons license and your intended use is not permitted by statutory regulation or exceeds the permitted use, you will need to obtain permission directly from the copyright holder. To view a copy of this license, visit http://creativecommons.org/licenses/by/4.0/.
\end{abstract}

(C) The Author(s) 2020 